\title{
Value system and life satisfaction: exploration of well-being amongst Indian students
}

\author{
Naisargi $\operatorname{Mehta}^{1} *$
}

\section{ABSTRACT}

This paper proposes to establish a connection between two variables - Value System and Life Satisfaction - amongst Indian students. Ten value types are measured based on Schwartz's Theory of Basic Values. A value, defined by Milton Rokeach (1973) is 'an enduring belief that a specific mode of conduct or end-state of existence is personally or socially preferable to an opposite or converse mode of conduct or end-state of existence'. While the dependent variable, as in life satisfaction refers to how comfortable an individual is with regards to the social, economic, religious/spiritual and personal aspects of their lives. The data was collected from 100 college-going students using the random sampling technique. For the purpose, two paper-pencil tests were used. One of the two tools was The Portrait Values Questionnaire (PVQ) by Shalom Schwartz (2001), which is used to measure an individual's value system. It comprises of 40 items and 10 variables, which include conformity, tradition, benevolence, universalism, self-direction, stimulation, hedonism, achievement, power and security. While the second instrument used was Sense of Coherence Scale from the "Satisfaction With Life Scale" (1985) which measures life satisfaction of an individual. It consists of 29 items and one factor, which is life satisfaction itself. Analysis of the collected data was done using Excel and SPSS. To analyze the collected data, a correlation was used. All of the values exhibited a negative correlation with life satisfaction. However, the correlation coefficient of stimulation, achievement, power, and security in comparison to life satisfaction was found to be the lowest.

Keywords: Life Satisfaction, Value System, Value Theory, Correlation Coefficient, Satisfaction With Life, Subjective Well-Being, SWB, LS, Portrait Value Questionnaire, PVQ, Satisfaction With Life Scale, SWLS

Study of any science is inextricable from philosophy. Social sciences are no exceptions to this. Rokeach thought along similar lines when he explained how the concept of values is the fundamental concept across all the social sciences. When you study culture and society, value is the most important dependent variable. Universal concepts such as society are ever dynamic. Hence, the collective value system of the humankind will adjust as the world does. If murdering someone is considered to be unethical now, it can be considered to be the most

\footnotetext{
${ }^{1}$ Undergraduate Student at the School of Liberal Studies (SLS), Pandit Deendayal Petroleum University *Responding Author
}

Received: December 29, 2019; Revision Received: January 19, 2020; Accepted: January 31, 2020

(C) 2020 Mehta. N; licensee IJIP. This is an Open Access Research distributed under the terms of the Creative Commons Attribution License (www.creativecommons.org/licenses/by/2.0), which permits unrestricted use, distribution, and reproduction in any Medium, provided the original work is properly cited. 
natural thing to do if the world is overpowered by any terrorist organisation. On the other hand, values are the independent variable if you study an individual. Your core values normally do not change and as a result of that, your attitude and behaviour towards people do. (Rokeach, 1973) A little after this, Inglehart showed us how it is not only social sciences that values have an influence upon. The advanced industrial society also leads to a shift in values. As political ideologies change, industries change as well. It is only recently that companies have started adopting the democratic system within themselves as a reflection of the rise of liberal ideology. (Inglehart, 1997) However, all of these observations could not land upon a standardized model for values.

It was not until Talcott Parsons, along with Edward A. Shills contributed his share in a book titled "Toward a General Theory of Action" that this field of research found some direction as to how the values affect the society as well as the individuals. In chapter 4 of the aforementioned book, Parsons explains that a social system is inclusive of a plurality of actors. Even though the basic set of rules that governs the society and the individuals is similar, the social system is discrete from the individual system. (Parsons, 2001) Now there was only one thing left to do, define the "basic set of rules". The social sciences lacked a universally agreed-upon conception of basic values, their structure and their interrelation. In 2006, Shalom Schwartz took it to himself to contribute a rational model to this decades-long discussion. (Schwartz S. H., 2006)

\section{Theory of Basic Values}

Schwartz came up with a model of 10 basic values. What he did differently than other experts was that he shone more light on how the importance of each value varies from individual to individual. Even though the set of values is the same, value A may be more important to person $\mathrm{X}$ than it is to person $\mathrm{Y}$. There are six main features that apply to all of the universal values and are acknowledged by many theorists. (Schwartz S. H., 2006)

1. Values are intricately linked to emotions. For example, equality is important for some people. If their right to equality is threatened, they become aroused and do everything in their might to protect it. Which brings us to the second point -

2. Values motivate action. In a company, some employees are self-motivated because power or security is important to them while some have to be motivated with material incentives because instant gratification is something that appeals to them.

3. Values go beyond societal norms and situations. This feature distinguishes values from narrower ideas like norms and attitudes that sometimes discuss with specific actions and/or objects.

4. All of your choices regarding situations, people and policies are guided by values. If you are compatible with another human being, it is most likely that your structure of values is common.

5. Importance of each of the values is relative to one another. The hierarchical structure of values defines your actions and choices.

6. Any action has consequences related to more than one value. The relative importance plays its part here. If value $\mathrm{A}$ is more significant than value $\mathrm{B}$, one may compromise the latter in order to stay true to the former.

Below are the 10 basic universal values according to Schwartz' theory:

\begin{tabular}{|c|l|}
\hline Value & \multicolumn{1}{c|}{ Description } \\
\hline Conformity & $\begin{array}{l}\text { Restraint of actions that have the possibility of harming others } \\
\text { and violating societal norms/expectations }\end{array}$ \\
\hline
\end{tabular}

(C) The International Journal of Indian Psychology, ISSN 2348-5396 (e)| ISSN: 2349-3429 (p) | 13 
Value system and life satisfaction: exploration of well-being amongst Indian students

\begin{tabular}{|c|c|}
\hline Value & Description \\
\hline Tradition & $\begin{array}{l}\text { Acceptance of and respect towards the customs and ideas of } \\
\text { one's culture and/or religion }\end{array}$ \\
\hline Benevolence & $\begin{array}{l}\text { A sense of kindness towards others, especially the 'in-group' } \\
\text { people }\end{array}$ \\
\hline Universalism & $\begin{array}{l}\text { Understanding and appreciation for the welfare of all the people } \\
\text { and for nature without any personal biases }\end{array}$ \\
\hline Self-direction & $\begin{array}{l}\text { Making choices independently that may lead to creation and } \\
\text { exploration }\end{array}$ \\
\hline Stimulation & The excitement towards change in life, novelty \\
\hline Hedonism & The pursuit of happiness, sensual self-indulgence \\
\hline Achievement & $\begin{array}{l}\text { Personal success through proving competence according to } \\
\text { social standards }\end{array}$ \\
\hline Power & Control and dominance of people, having a social status \\
\hline Security & $\begin{array}{l}\text { Safety, harmony, and stability of society, of relationships, and of } \\
\text { self. }\end{array}$ \\
\hline
\end{tabular}

\section{Figure 1 Schwartz' Original Classification}

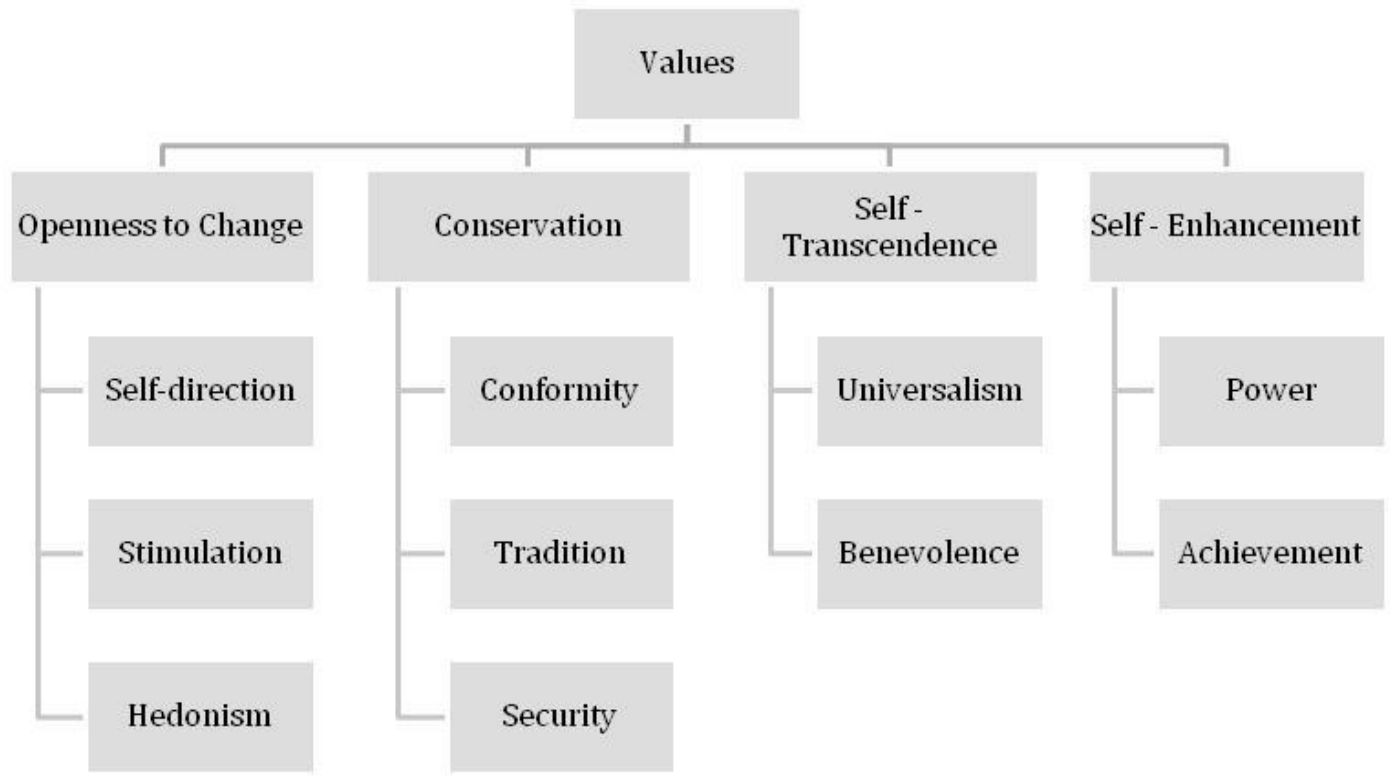

Schwartz original classification of values conveys oppositions between Openness to Change and Conservation and Self-Transcendence to Self-Enhancement values. However, in 2006, Schwartz proposed an alternative dimensional organisation of values on the basis of selfinterest and interest of others, as shown in figure 2. (Sortheix \& Lönnqvist, 2014)

\section{Satisfaction With Life Scale (SWLS)}

The question of how to measure the quality of one's life has been evolving since the 18th Century. It was only after the 20th Century that life satisfaction stopped being associated with material gratification. (Prasoon \& Chaturvedi, 2016) This growing area of research initiated with the study of the concept of subjective well-being (SWB). Subjective well-being is a multidimensional field, one of these dimensions being life satisfaction. Life satisfaction has been defined as, even though a part of SWB, an independent construct representing a cognitive and universal evaluation of the quality of one's life as a whole. Developed in 1985, the Satisfaction With Life Scale (SWLS) was originally put together by Diener, Emmons, Larsen, and Griffin. (Pavot \& Diener, 2008) 
Figure 2 Schwartz' Modifies Classification

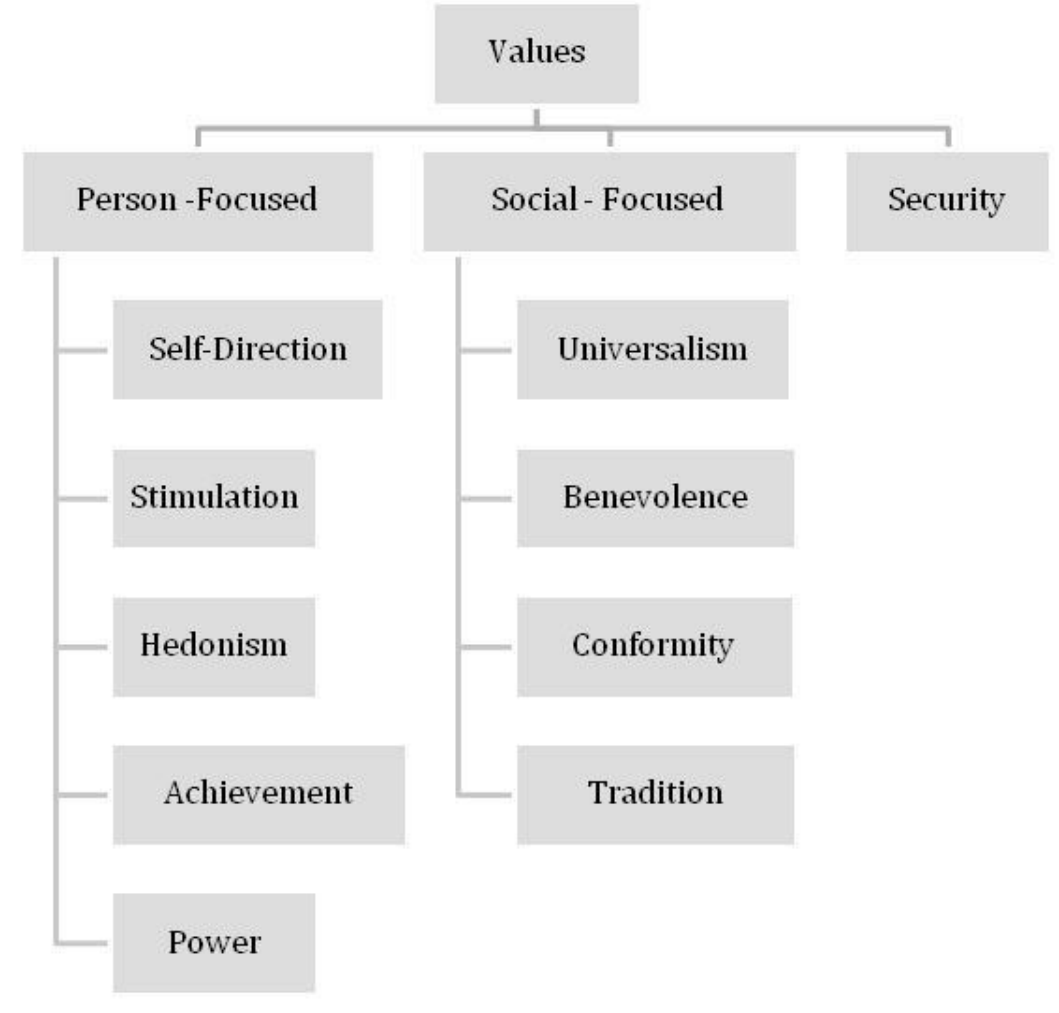

This study aims to combine the aforementioned concepts of value theory and life satisfaction (LS) in order to find a possible correlation that may affect the routine life of people between the age of 18 and 26. According to Erik Erikson's theory of psychological stages, the identity crisis in humans occurs between the age of 12 to 18 , while the next stage of 18 to 40 is devoted to forming loving relationships with people. (McLeod, 2017) The age group selected in this study falls somewhere between stage five (Identity vs. Role Confusion) and stage six (Intimacy vs. Isolation). It is the age of seeking the true meaning of happiness and the initiating the quest for achieving the same. The first step of this quest for truth and joy is introspection. The tools involved in this study gently try to probe the participants to think deeply about their values and how/whether they are affecting their lives.

\section{LITERATURE REVIEW}

According to some authors, researchers have inequitably focused on the study of psychological ill-being. There have been suggestions that psychologists should give more importance to the complementary study of subjective well-being (SWB). (Huebner, April 2004) Unlike what was believed in the 19th Century, income is not the ultimate measurement for life satisfaction. In a study done on the determinants of life satisfaction in Asia, it was interestingly found that many factors omitting the income such as marital status, the standard of living, and role of government have a greater influence on people's overall satisfaction with life. (Ngoo, Tey, \& Tan, October 2015) Narrowing down to a universally accepted module of values was a feat that required years of worldwide research. In 2003, Dario Spini set out to evaluate the measurement equivalence of the 10 value types described in Schwartz theory across 21 countries. Most of the values reached acceptable levels of metric as well as configural levels of equivalence while Hedonism rejected at these two levels. All of the value types, on the other hand, rejected scalar and reliability equivalence. (Spini, January 2003) 
The very first time that values and life satisfaction were considered to be interrelated can be traced as back as 1998. That was before the development of the basic value theory. Gary Bowen, in his study of family relations first guessed that people's values towards their families, the differences in the intra-family values, and differences in value priority is related to family's life satisfaction. Discordance in the family's collective value system was hypothesized to negatively impact the family's psychological well-being. (Bowen, October 1998) Again in April 2004, there was a brief indication of this while conducting a study on children from 12 to 16 years. In kids, general life satisfaction is shown to be positively correlated with non-materialistic values. (Casas, González, Figuer, \& Coenders, April 2004) These studies, albeit important were not enough. Psychologists witnessed a breakthrough in this area in 2009. One of the many articles in the Social Indicators Research Journal was about the correlation between income, reference income and life satisfaction. Interestingly enough, that study proved the correspondence between not only values and subjective wellbeing, but it also discovered that values were the mitigating factors in the link between income, reference income and life satisfaction. In simpler words, the study observed that it is not the individual income that affects life satisfaction negatively, it is the reference/comparison income (person A's income in relation to person B's) that has an adverse effect on psychological well-being. However, it also uncovered the secret ingredient to easing up the tension between the aforementioned three variables: values. If one's values are strong enough, the comparison income cannot even touch their satisfaction with life. (Georgellis, Tsitsianis, \& Yin, May 2009) The same year, Mohsen Joshanloo and Gholamhossein Ghaedi conducted a study on 200 Iranian university students. They divided life satisfaction into two parts: hedonic (affect balance and life satisfaction) and eudaimonic (psychological and social well-being). According to the results, achievement and tradition values were positively correlated with both eudaimonic and hedonic aspects of well-being. While power, self-direction, universalism, benevolence and conformity values were related only to the eudaimonic aspects of well-being. (Mohsen \& Gholamhossein, 2009)

A study done on European countries considered the original classification of values and discovered that psychological well-being was concordant with openness to change values while it was negatively associated with conservation values. The relations between selftranscendence/self-enhancement and life satisfaction were small and incongruous. (Bobowik, Basabe, Pa'ez, Jime'nez, \& Bilbao, 2011) However, Florencia M. Sortheix and Jan-Erik Lönnqvist again evaluated value priorities and life satisfaction across 25 European countries in 2013. Socioeconomic development was an additional variable in their study. Their belief was that considering the context in which the values are sought can give us further insights about how the values affect well-being. They termed this as "Value-Environment Fit". To assess the countries' socioeconomic well-being, they referred to the Human Development Index (HDI). Benevolence and hedonism were found to be positively correlated with LS whereas power and security were negatively correlated. In low HDI countries, achievement was in positive association with LS while universalism was negatively related. Contradictorily, achievement showed negative relations with LS in high HDI countries, while power and security in concordance. (Sortheix \& Lönnqvist, 2014)

\section{AIM OF THE STUDY}

This study aims to find the relationship, if any, between a.) ten universal values as defined in Schwartz Theory of Basic Values and b.) life satisfaction according to Pavot and Diener's Satisfaction With Life Scale (SWLS). The research topic of anticipating a correspondence between our values and satisfaction with life is still quite young. It has been tested in Iran and 25 countries of Europe. Similar studies were conducted in 2009, 2011 and 2014 the results of 
which have contributed to their nations' growth. (Mohsen \& Gholamhossein, 2009) (Bobowik, Basabe, Pa'ez, Jime'nez, \& Bilbao, 2011) (Sortheix \& Lönnqvist, 2014) The result of this study can not only help the Indian government and organizations with their policies and strategies but also help individuals introspect more methodically.

\section{HYPOTHESES}

Null Hypotheses:

1. There is no significant correlation between an individual's conformity and their satisfaction with life.

2. There is no significant correlation between an individual's tradition and their satisfaction with life.

3. There is no significant correlation between an individual's benevolence and their satisfaction with life.

4. There is no significant correlation between an individual's universalism and their satisfaction with life.

5. There is no significant correlation between an individual's self-direction and their satisfaction with life.

6. There is no significant correlation between an individual's stimulation and satisfaction with life.

7. There is no significant correlation between an individual's hedonism and their satisfaction with life.

8. There is no significant correlation between an individual's achievement and their satisfaction with life.

9. There is no significant correlation between an individual's power and their satisfaction with life.

10. There is no significant correlation between an individual's security and satisfaction with life.

\section{METHODOLOGY}

Sample

100 college-going students that fall under the age range of 18-26

\section{Tools}

Two measures were used in this study.

1. The Portrait Values Questionnaire(PVQ) (Schwartz, Beierlein, Davidov, \& Schmidt, 2012)

The questionnaire comprises of 40 items and ten variables. The variables are defined as given below:

$\checkmark$ Conformity - Restraint of actions that have the possibility of harming others and violating societal norms/expectations

$\checkmark$ Tradition - Acceptance of and respect towards the customs and ideas of one's culture and/or religion

$\checkmark$ Benevolence - A sense of kindness towards others, especially the 'in-group' people

$\checkmark$ Universalism - Understanding and appreciation for the welfare of all the people and for nature without any personal biases

$\checkmark$ Self-Direction - Making choices independently that may lead to creation and exploration

$\checkmark$ Stimulation - Excitement towards change in life, novelty

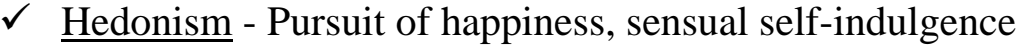




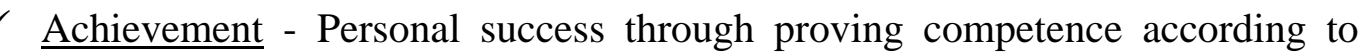
social standards

$\checkmark$ Power - Control and dominance of people, having a social status

$\checkmark$ Security - Safety, harmony, and stability of society, of relationships, and of self.

\section{Sense of Coherence Scale from the "Satisfaction With Life Scale" (Pavot \&} Diener, 2008)

\section{Validity}

Both of the scales have been used extensively in different parts of the world to conduct various psychological studies. The PVQ has been tested in over 21 different countries including Canada, Argentina, India, UK, Italy and Switzerland resulting in an evaluation of 3787 PVQs. The results indicate that most value types reach acceptable levels of equivalence. (Spini, January 2003) The validity of SWLS was tested across Washington, Oregon and Germany resulting in a combined sample size of 16,653. This study had procured results that proved SWLS to be reliable. (Cheung \& Lucas, 2014)

\section{Sampling Technique}

Simple random sampling - it is a sampling technique where all of the individuals that are included in the population have an even chance of being selected in the sample.

\section{RESULTS}

The results obtained after running correlation on the collected data exhibited a negative correlation between all of the ten values and LS. All of the ten hypotheses have been rejected.

Table 1

\begin{tabular}{|l|l|l|l|}
\hline LS vs. Conformity & & Conformity & Life Satisfaction \\
\hline & Conformity & 1 & -0.19902024 \\
\hline & Life Satisfaction & -0.19902024 & 1 \\
\hline
\end{tabular}

According to this table, null hypothesis 1 has been rejected. Conformity has a negative relationship with LS. If one restraints actions that may harm the other, their life satisfaction goes down. Which can be justified because even though for societal benefit, an individual's freedom of speech is being impaired.

Table 2

\begin{tabular}{|l|l|l|l|}
\hline LS vs. Tradition & & & \\
\hline & & Tradition & Life Satisfaction \\
\hline & Tradition & 1 & -0.14977538 \\
\hline & Life Satisfaction & -0.14977538 & 1 \\
\hline
\end{tabular}

According to this table, null hypothesis 2 has been rejected. Tradition has a negative relationship with LS. An individual's acceptance of their culture and/or religion's ideas and customs leads to lower satisfaction with life.

Table 3

\begin{tabular}{|l|l|l|l|}
\hline LS vs. Benevolence & & & \\
\hline & & Benevolence & Life Satisfaction \\
\hline & Benevolence & 1 & -0.23876126 \\
\hline & Life Satisfaction & -0.23876126 & 1 \\
\hline
\end{tabular}

(C) The International Journal of Indian Psychology, ISSN 2348-5396 (e)| ISSN: 2349-3429 (p) | 18 
According to this table, null hypothesis 3 has been rejected. Benevolence has a negative relationship with LS. If one exhibits a sense of kindness towards others, it signifies that their satisfaction with life is low.

Table 4

\begin{tabular}{|l|l|l|l|}
\hline LS vs. Universalism & & & \\
\hline & & Universalism & Life Satisfaction \\
\hline & Universalism & 1 & -0.14001171 \\
\hline & Life Satisfaction & -0.14001171 & 1 \\
\hline
\end{tabular}

According to this table, null hypothesis 4 has been rejected. Universalism has a negative relationship with LS. If one exhibits a sense of understanding and appreciation towards others while staying unaffected by personal biases, it signifies that their satisfaction with life is low.

Table 5

\begin{tabular}{|l|l|l|l|}
\hline LS vs. Self-Direction & & & \\
\hline & & Self-direction & Life Satisfaction \\
\hline & Self-direction & 1 & -0.09710791 \\
\hline & Life Satisfaction & -0.09710791 & 1 \\
\hline
\end{tabular}

According to this table, null hypothesis 5 has been rejected. Self-direction has a negative relationship with LS. Making independent choices that lead to innovative solutions leads to lower satisfaction with life. This signifies the collectivist attitude among the population.

Table 6

\begin{tabular}{|l|l|l|l|}
\hline LS vs. Stimulation & & & \\
\hline & & Stimulation & Life Satisfaction \\
\hline & Stimulation & 1 & -0.32161372 \\
\hline & Life Satisfaction & -0.32161372 & 1 \\
\hline
\end{tabular}

According to this table, null hypothesis 6 has been rejected. Stimulation has a negative relationship with LS. Novelty experiences in one's life lead to lower satisfaction with life.

Table 7

\begin{tabular}{|l|l|l|l|}
\hline LS vs. Hedonism & & & \\
\hline & & Hedonism & Life Satisfaction \\
\hline & Hedonism & 1 & -0.22171382 \\
\hline & Life Satisfaction & -0.22171382 & 1 \\
\hline
\end{tabular}

According to this table, null hypothesis 7 has been rejected. Hedonism has a negative relationship with LS. Surprisingly, one's pursuit of their own happiness leads to lower satisfaction with life.

Table 8

\begin{tabular}{|l|l|l|l|}
\hline LS vs. Achievement & & & \\
\hline & & Achievement & Life Satisfaction \\
\hline & Achievement & 1 & -0.38261784 \\
\hline & Life Satisfaction & -0.38261784 & 1 \\
\hline
\end{tabular}

(C) The International Journal of Indian Psychology, ISSN 2348-5396 (e)| ISSN: 2349-3429 (p) | 19 
According to this table, null hypothesis 8 has been rejected. Achievement has a negative relationship with LS. Personal success by proving one's worth to society's standards leads to lower satisfaction with life.

Table 9

\begin{tabular}{|l|l|l|l|}
\hline LS vs. Power & & & \\
\hline & & Power & Life Satisfaction \\
\hline & Power & 1 & -0.29439684 \\
\hline & Life Satisfaction & -0.29439684 & 1 \\
\hline
\end{tabular}

According to this table, null hypothesis 9 has been rejected. Power has a negative relationship with LS. Control and dominance over people lead to lower satisfaction with life.

Table 10

\begin{tabular}{|l|l|l|l|}
\hline LS vs. Security & & & \\
\hline & & Security & Life Satisfaction \\
\hline & Security & 1 & -0.35318947 \\
\hline & Life Satisfaction & -0.35318947 & 1 \\
\hline
\end{tabular}

According to this table, null hypothesis 10 has been rejected. Security has a negative relationship with LS. A sense of stability in society, relationships and even oneself leads to lower satisfaction with life.

\section{DISCUSSION}

All of the values that come under Schwartz' Theory of Basic Values evince a negative correlation with LS with regards to this study. However, stimulation, achievement, power and security show a stronger correlation coefficient amongst all. These four values, according to figure 2 showing Schwartz' Modified Classification come under the term "Person-Focused Values". Neither person-focused nor social-focused values have led to high LS in the current study.

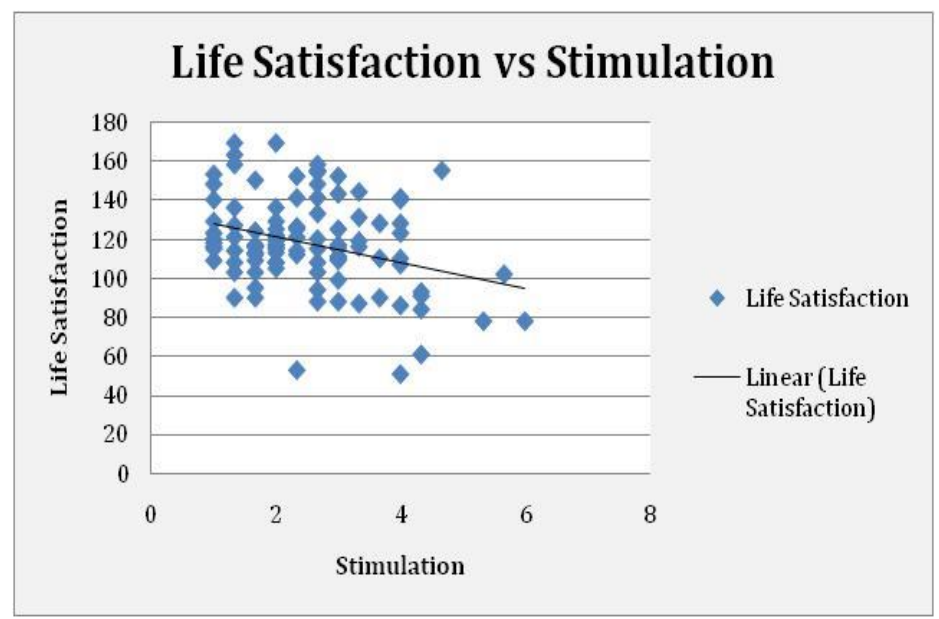

\section{LS vs. Stimulation}

Stimulation, according to Schwartz's theory means "Excitement towards change in life, novelty". For the sample selected in this study, life satisfaction decreases as stimulation increases. This is surprising seeing how new adventures and experiences in life are considered to be more desired among the youth. It could be a possibility that the respondents' only seek stimulation for social desirability and not for self-satisfaction. 

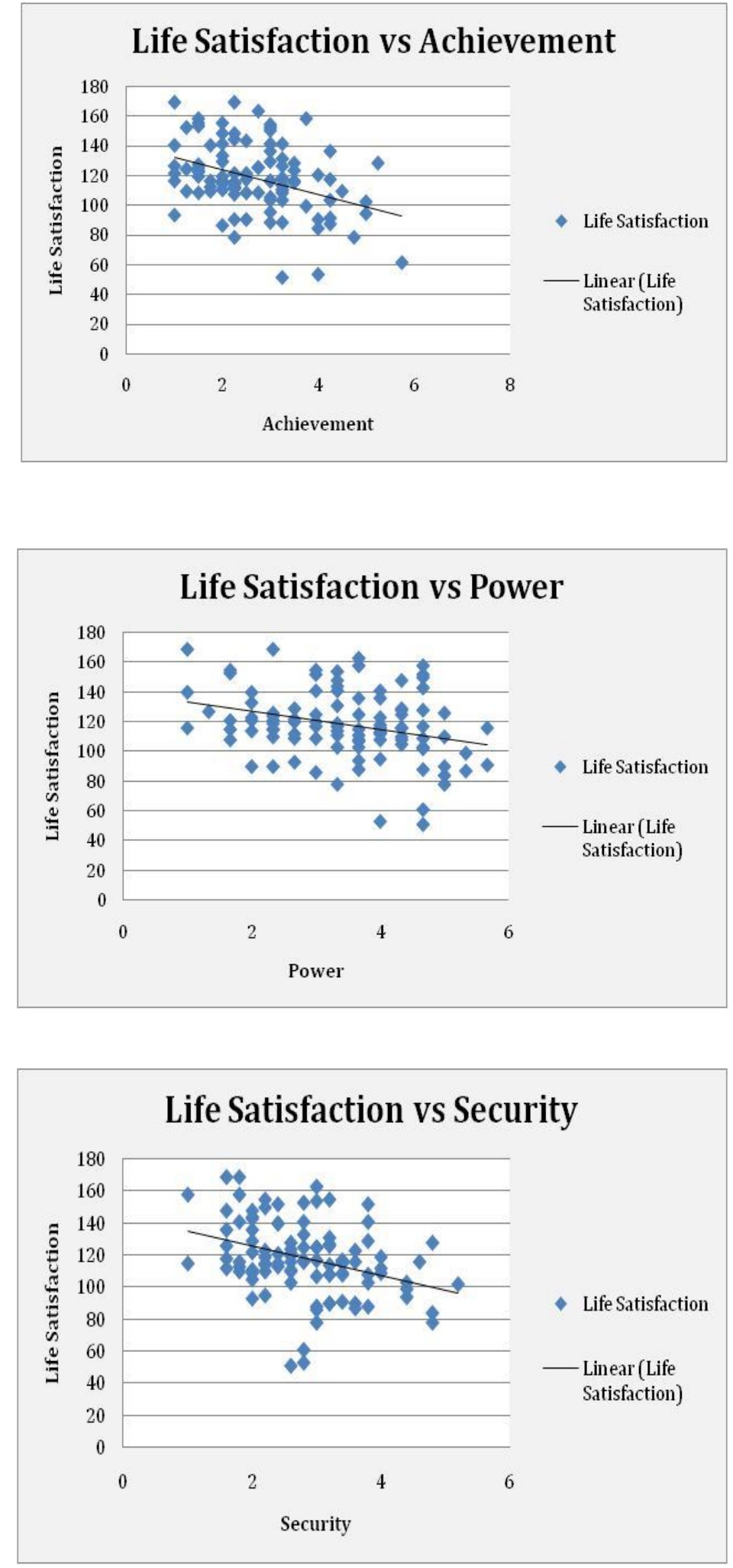

to lower respondents' LS

\section{LS vs. Achievement}

Achievement, according to Schwartz's theory means "Personal success through proving competence according to social standards." For the sample selected in this study, LS and Achievement are negatively correlated. The correlation coefficient between Achievement and LS is the lowest among all. This signifies that socially accepted means of achievement are no longer in alignment with an individual's own goals.

\section{LS vs. Power}

Power, according to Schwartz's theory means - "Control and dominance of people, having a social status." For the sample selected in this study, LS and Power are negatively correlated. This signifies that Indian students of the age group 18-26 have less desire for a powerful social status. It may be due to the evolution of India's ideology. Individualism is becoming more prevalent in India than it was in the 1900s.

\section{LS vs. Security}

Security, according to Schwartz's theory means - "Safety, harmony, and stability of society, of relationships, and of self." For the sample selected in this study, LS and Security are negatively correlated. This result may be a product of the age group. The students, who are already under the shelter of a university, do not desire stability or safety. However, this contradicts the previous finding where even the adventures and new experiences (stimulation) were found

In a similar study conducted in 2014, the results were in line with the results of the ongoing study. It showed that power and security lead to lower satisfaction with life in 25 European countries. In low HDI (Human Development Index) countries in Europe, achievement leads to low LS, equivalent to the current study. (Sortheix \& Lönnqvist, 2014) 


\section{CONCLUSION}

The life satisfaction of Indian students between the age of 18 and 26 has a negative correlation with their basic values. In simple words, the stronger one's values, lesser satisfied with the life they are. Strikingly strong relation is found between LS and four of the ten basic values - stimulation, achievement, power and security.

\section{LIMITATIONS AND FUTURE SCOPE}

1. There may be a difference of understanding between the values defined by Schwartz in his theory and the values perceived by the selected sample.

2. The sample size is limited when compared to the population.

3. A similar study can be done in different regions of India to form a national index of values and their effects on life satisfaction of Indian citizens. This will help the nation identify the cause of low life satisfaction and develop and/or modify national strategies and policies accordingly.

\section{ACKNOWLEDGEMENTS}

During the course of this study, many organisations, as well as individuals, have played an important part in its completion. This section represents an expression of gratitude to everyone because of whom this study could be executed.

1. Faculty of Psychology, PDPU for guiding the author through every single step in her first-ever attempt at a research study.

2. School of Liberal Studies, PDPU for providing a strong and abiding support system.

3. InSPA for providing a platform to present the findings upon.

4. Dr Neeta Sinha, Rishi Bhandari and Soni Mittal for accurate guidance.

5. Dr Sudipta Roy for providing practical advice as a senior member in the field.

6. Dr Dharmendra Sheth for linguistic support.

\section{REFERENCES}

Bobowik, M., Basabe, N., Pa'ez, D., Jiménez, A., \& Bilbao, M. A. (2011). Personal Values and Well-Being among Europeans, Spanish Natives and Immigrants to Spain: Does the Culture Matter? Journal of Happiness Studies, DOI: 10.1007/s10902-010-9202-1; Pages: 401-419.

Inglehart, R. (1997). Modernization and Postmodernization: Cultural, Economic, and Political Change in 43 Societies. Michigan: Princeton University Press.

Mohsen, J., \& Gholamhossein, G. (2009). Value priorities as predictors of hedonic and eudaimonic aspects of well-being. Personality and Individual Differences, DOI: 10.1016/j.paid.2009.03.016; Pages: 294-298.

Parsons, T. (2001). The Social System. In R. Carkhuff, Toward a General Theory of Action (p. 44). New York: Routledge.

Prasoon, R., \& Chaturvedi, K. R. (2016). Life Satisfaction: A Literature Review. International Journal of Management Humanities and Social Sciences, Pages: 25-32.

Rokeach. (1973). The nature of human values. PsycINFO Database Record; DOI: 0029267501 .

Schwartz, S. H. (2006). Basic Human Values: Theory, Measurement, and Applications. Revue française de Sociologie, 47/4, DOI: 10.3917/rfs.474.0929; Page: 51.

Schwartz, S. H., Beierlein, C., Davidov, E., \& Schmidt, P. (2012, April 25). Testing the discriminant validity of Schwartz' Portrait Value Questionnaire items. Survey Research Methods Vol.6, No.1, DOI: https://doi.org/10.18148/srm/2012.v6i1.5092; Pages: 25-36. 
Sortheix, F. M., \& Lönnqvist, J.-E. (2014). Personal Value Priorities and Life Satisfaction in Europe: The Moderating Role of Socioeconomic Development. Journal of CrossCultural Psychology, DOI: 10.1177/0022022113504621; Pages: 282-299.

Bowen, G. L. (October 1998). Family Life Satisfaction: A Value-Based Approach. Family Relations vol. 37, DOI: 10.2307/584120; Pages: 458-462.

Spini, D. (January 2003). Measurement Equivalence Of 10 Value Types From The Schwartz Value Survey Across 21 Countries. Journal of Cross-Cultural Psychology, DOI: 10.1177/0022022102239152; Pages: 3-23.

Casas, F., González, M., Figuer, C., \& Coenders, G. (April 2004). Subjective Well-Being, Values and Goal Achievement: The Case of Planned versus by Chance Searches on the Internet. Social Indicators Research, Vol. 66, DOI: 10.1023/B:SOCI.0000007492.61737.46; Pages: 123-141.

Huebner, E. S. (April 2004). Research on Assessment of Life Satisfaction of Children and Adolescents. Social Indicators Research, DOI: 10.1023/B:SOCI.0000007497.57754.e3; Pages: 3-33.

Pavot, W., \& Diener, E. (2008, April). The Satisfaction With Life Scale and the emerging. The Journal of Positive Psychology, DOI: 10.1080/17439760701756946; Pages: 137152.

Georgellis, Y., Tsitsianis, N., \& Yin, Y. P. (May 2009). Personal Values as Mitigating Factors in the Link between Income and Life Satisfaction: Evidence from the European Social Survey. Social Indicators Research, Vol. 91, DOI: 10.1007/s11205008-9344-2; Pages: 329-344.

Cheung, F., \& Lucas, R. E. (2014, December). Assessing the validity of single-item life satisfaction measures: results from three large samples. Quality of Life Research, Vol. 23, No 10, DOI: 10.1007/s11136-014-0726-4 .

Ngoo, Y. T., Tey, N. P., \& Tan, E. C. (October 2015). Determinants of Life Satisfaction in Asia. Social Indicators Research, DOI: 10.1007/s11205-014-0772-x; Pages: 141-156.

McLeod, S. (2017, February). Erik Erikson's Stages of Psychosocial Development, Pages: 15.

\section{Acknowledgements}

The authors profoundly appreciate all the people who have successfully contributed in ensuring this paper is in place. Their contributions are acknowledged however their names cannot be mentioned.

\section{Conflict of Interest}

The authors colorfully declare this paper to bear no conflict of interests

How to cite this article: Mehta. N, (2020). Value system and life satisfaction: exploration of well-being amongst Indian students. International Journal of Indian Psychology, 8(1), 12-23. DIP:18.01.002/20200801, DOI:10.25215/0801.002 